\title{
PELAKSANAAN SUPERVISI AKADEMIK PENGAWAS SEKOLAH SEBAGAI UPAYA PENINGKATAN PROFESIONALISME GURU
}

\author{
${ }^{1}$ Messi, ${ }^{2}$ Wiwin Anggita Sari, \& ${ }^{3}$ Murniyati \\ ${ }^{1}$ MAN 3 Palembang ${ }^{2,3}$ Universitas PGRI Palembang \\ e-mail: ${ }^{1}$ messiyuliyu@gmail.com ${ }^{2}$ wiwinanggita06@gmail.com ${ }^{3}$ murnipgriagus@gmail.com
}

Abstract: Academic supervision is an activity planned to help teachers in the learning process in order to improve students' learning outcomes. This study aimed at investigating the supervision of school's supervisor in improving the professionalism of teachers and improve the quality of education at SMP Negeri 44 Palembang. The type of this research is qualitative and the data were obtained by observation, documentation and interview. The results of this study (1) supervision conducted by applying the official approach, partners, and kinship, and the techniques developed by supervisors in implementing academic supervision vary considerably; (2) supervisory obstacles in carrying out academic supervision is the number of teachers were too many, however it only had limited time; (3) the implementation of general academic supervision is good enough and able to carry out its duties and functions properly; (4) aspects that have been targeted by the supervision of school's supervisors are still limited, not all aspects of academic supervision; (5) the frequency of visits by school's supervisors in conducting academic supervision is considered lack because it is not evenly distributed; teachers receive class visits by supervisors; and (6) efforts made by supervisors in carrying out academic supervision at SMP Negeri 44 Palembang have not been optimal in providing guidance to teachers.

Keywords: Academic Supervision; School's Supervisor; Teachers'Profesionalism

\section{PENDAHULUAN}

Pendidikan bertujuan untuk meningkatkan kualitas sumber daya manusia sebagaimana yang telah digariskan melalui Undang Undang No. 20 Tahun 2003. Salah satu usaha untuk meningkatkan kualitas sumber daya manusia yaitu melalui proses pembelajaran di sekolah. Dalam usaha meningkatkan kualitas sumber daya manusia, guru merupakan komponen yang harus dibina dan dikembangkan terus menerus. Maka dari itu agar para guru mampu melaksanakan tugas-tugasnya di sekolah perlu senantiasa mendapat penyegaran dalam bentuk bantuan teknis. Bantuan teknis ini diberikan kepada guru sebagai upaya untuk peningkatan kapasitas secara terus menerus. Bantuan tersebut dapat digunakan dalam bentuk supervisi akademik yang dilakukan oleh pengawas sekolah dalam rangka perbaikan kinerja guru supaya dapat mencapai tujuan pendidikan nasional.

Supervisi akademik merupakan kegiatan terencana yang ditujukan pada aspek kualitatif sekolah dengan membantu guru melalui dukungan dan evaluasi pada proses pembelajaran agar dapat meningkatkan hasil belajar siswa. Supervisi akademik merupakan serangkaian kegiatan membantu guru dalam mengembangkan kemampuanya untuk mengelola proses pembelajaran demi pencapaian tujuan pembelajaran yang akan di 
capai (Dirjen PMPTK Diknas, 2008: 9). Pembinaan lebih diarahkan pada upaya memperbaiki dan meningkatkan kemampuan profesional guru. Guru profesional memiliki pengalaman mengajar, moral, kapasitas intelektual, keimanan, disiplin, ketaqwaan, wawasan kependidikan yang luas, kemampuan manajerial, terampil, kreatif, tanggungjawab, memiliki keterbukaan profesional dalam memahami potensi, karakteristik dan masalah perkembangan peserta didik, mampu mengembangkan rencana studi dan karir peserta didik serta memiliki kemampuan meneliti dan mengembangkan kurikulum.

Unsur utama dari pelaksanaan supervisi yaitu pembinaan yang dilakukan pengawas sekolah kepada semua guru di sekolah binaannya tersebut. Melalui kegiatan supervise, guru mendapatkan arahan, bimbingan dan pembinaan dari pengawas sekolah untuk berbagai kendala yang dialami dalam melaksanakan tugasnya di sekolah.

Supervisi akademik sebagai Instructional Supervision atau Instructional Leadership fokusnya adalah menilai, mengkaji, meningkatkan, memperbaiki dan mengembangkan mutu kegiatan belajarmengajar yang dilakukan guru melalui pendekatan bimbingan dan konsultasi dalam nuansa dialog profesional. Pengawasan atau supervisi pendidikan merupakan usaha memberikan layanan kepada stakeholder pendidikan, terutama kepada guru-guru, baik secara invidu maupun secara kelompok dalam usaha memperbaiki kualitas proses dan hasil pembelajaran (Sagala, 2010:15).

Secara sederhana, menurut Jerry (2011: 76) prinsip-prinsip supervisi yaitu (1) pelaksanaan supervisi hendaknya terjalin hubungan profesional; (2) supervisi berdasarkan sikap, kesanggupan, kondisi dan kemampuan; dan (3) menolong guru agar senantiasa tumbuh sendiri tidak tergantung pada pihak kepala sekolah; (4) memberikan rasa aman; (5) bersifat konstruktif dan kreatif; (6) keadaan dan kenyataan sebenarnya; dan (7) kegiatannya terlaksana dengan sederhana. Sasaran supervisi akademik antara lain untuk membantu guru dalam hal (a) melayani peserta didik yang mengalami kesulitan belajar; (b) memberikan bimbingan belajar; (c) menciptakan lingkungan belajar yang nyaman; (d) mengembangkan dan memanfaatkan alat bantu dan media pembelajaran; (e) mengembangkan interaksi yang tepat dan berdaya guna; (f) merencanakan kegiatan pembelajaran; (g) melaksanakan kegiatan pembelajaran; (h) menilai proses dan hasil pembelajaran; (i) memanfaatkan untuk penilaian meningkatkan layanan pembelajaran; (j) memberikan umpan balik secara baik; (k) melakukan penelitian bagi perbaikan pembelajaran/bimbingan dan 
mengembangkan inovasi pembelajaran/ bimbingan Jerry (2011: 8).

Dalam pelaksanakan supervisi akademik, pengawas sekolah harus mengetahui dan memahami serta melaksanakan teknik-teknik dalam supervisi. Berbagai teknik yang dapat digunakan oleh pengawas sekolah baik secara kelompok maupun secara perorangan adalah dengan cara langsung bertatap muka dan cara tak langsung bertatap muka atau melalui media komunikasi (Sagala, 2010:174).

Pengawas sekolah merupakan guru yang diangkat Pegawai Negeri Sipil yang diangkat dalam jabatan pengawas di sekolah. Kegiatan pengawas sekolah adalah menyusun program, melaksanakan program pengawasan, evaluasi hasil pelaksanaan program, dan melaksanakan pembimbingan dan pelatihan profesional guru (PP 74 tahun 2008).

Sagala (2010: 281) mengatakan bahwa pengawas sekolah merupakan tenaga kependidikan profesional yang diberi tanggung jawab, tugas, dan wewenang secara penuh oleh pejabat yang berwenang untuk melakukan pembinaan dan pengawasan dalam bidang akademik maupun bidang manajerial. Tugas pokok Pengawas Sekolah Sesuai dengan PP 74 tahun 2008 adalah melakukan tugas pengawasan akademik dan manajerial serta tugas pembimbingan dan pelatihan profesional guru.
Guru sebagai pendidik merupakan tenaga profesional yang bertugas merencanakan dan melaksanakan proses pembelajaran, menilai hasil pembelajaran, melakukan bimbingan dan pelatihan serta melakukan penelitian dan pengabdian kepada masyarakat. Guru wajib mengembangkan dan memanfaatkan kemampuan profesionalnya, sehingga dapat meningkatkan kinerja dalam melaksanakan tugas dan fungsionalnya karena pendidikan masa datang menuntut keterampilan profesi pendidik yang berkualitas (Nurhayati, 2006:64).

Menurut Daryanto (2009: 253) profesionalisme berasal dari kata profesi yang artinya suatu bidang pekerjaan yang ingin atau akan ditekuni oleh seseorang tetapi memerlukan persiapan melalui pendidikan dan pelatihan secara khusus. Profesional merupakan kegiatan yang dilakukan oleh seseorang dan menjadi sumber pendapatan kehidupan yang memerlukan keahlian khusus, kemahiran atau kecakapan yang memenuhi standar mutu yang akan dicapai.

Makawimbang (2011:134) mengatakan bahwa guru yang profesional merupakan mereka yang memiliki kemampuan profesional dengan berbagai kapasitasnya sebagai pendidik. Guru yang profesional amat berarti bagi pembentukan sekolah unggulan. Guru profesional memiliki pengalaman mengajar, kapasitas intelektual, moral, 
keimanan, ketakwaan, disiplin, tanggungjawab, wawasan kependidikan yang luas, kemampuan manajerial, terampil, kreatif, memiliki keterbukaan profesional dalam memahami potensi dan karakteristik.

Menurut Daryanto (2009: 254), guru yang profesional yakni guru yang memiliki kompetensi yang dipersyaratkan untuk melakukan tugas pendidikan dan pengajaran. Kompetensi di sini meliputi pengetahuan, sikap, dan keterampilan profesional, baik yang bersifat pribadi, sosial maupun akademis.

Studi yang dilakukan oleh Ace Suryani (Makawimbang, 2011: 13) menunjukkan bahwa guru yang bermutu dapat diukur dengan lima indicator antara lain (1) kemampuan profesional (professional capacity), sebagaimana terukur dari ijazah, jenjang pendidikan, jabatan dan golongan, serta pelatihan; (2) upaya profesional (professional efforts), sebagaimana terukur dari kegiatan mengajar, pengabdian dan penelitian; (3) waktu yang dicurahkan untuk kegiatan profesional (teacher's time), sebagaimana terukur dari masa jabatan, pengalaman mengajar; (4) tingkat kesejahteraan (prosperiousity) sebagaimana terukur dari upah, honor atau penghasilan rutinnya keahlian dan pekerjaannya (link and match); (5) sebagaimana terukur dari mata pelajaran yang telah sesuai dengan spesialisasinya. Tingkat kesejahteraan yang rendah bisa mendorong seorang pendidik untuk melakukan kerja tambahan, dan bilamana kerja tambahan ini sukses, bisa jadi profesi mengajarnya berubah menjadi tambahan.

Mutu merupakan conformance to requirement, yaitu sesuatu dengan yang disyaratkan atau distandarkan. Boleh juga diartikan bahwa "mutu yakni kesesuaian terhadap permintaan persyaratan (The Conformance of Requirements" Philip B. Crosby (Makawimbang, 2011:44). Sedangkan Garvin dan Davis juga menyebutkan bahwa mutu adalah suatu kondisi dinamis yang berhubungan dengan produk, tenaga kerja, proses dan tugas, serta lingkungan yang memenuhi atau melebihi harapan pelanggan atau konsumen yang sudah ada (Makawimbang, 2011: 44).

Makawimbang (2011: 42) mengatakan peningkatan mutu merupakan dambaan Negara dalam menyelenggarakan pendidikannya. Upaya peningkatan mutu itu tidaklah mudah, demikian pakar mutu menyatakan kesungguhannya. Meningkatkan mutu perlu rumusan pikiran tentang apa yang hendak ditingkatkan, memilih bagian yang paling dibutuhkan pelanggan, dan menghasilkan produk kegiatan yang paling unggul di antara produk sejenis. Oleh sebab itu, peningkatan mutu memerlukan ide baru yang datang dari pikiran cerdas, selalu 
mengandung bagian yang berbeda dari yang ada sebelumnya, menghasilkan bagian yang lebih sempurna, lebih bermanfaat, lebih mempermudah sehingga lebih diminati. Menurut Kristiawan dkk (2017) Mutu dalam produk tidak akan dihasilkan tanpa pengendalian mutu di dalam proses. Mutu di dalam proses tidak akan terjamin tanpa organisasi yang tepat dan efektif. Organisasi yang tepat dan efektif tidak ada artinya tanpa pemimpin yang memadai.

\section{METODE PENELITIAN}

Penelitian ini adalah penelitian kualitatif. Menurut Sugiyono (2009:1), penelitian kualitatif merupakan suatu metode yang digunakan untuk meneliti pada kondisi objek yang alamiah, di mana peneliti merupakan sebagai instrumen kunci, teknik pengumpulan data dilakukan secara triangulasi (gabungan), sifat analisis data dan hasil penelitian kualitatif lebih menekankan makna daripada generalisasi. Menurut Kristiawan dan Elnanda (2017) qualitative is one of research procedure that produces descriptive data in form of words, writing, and behavior of the people being observed. Proses penelitian ini menggunakan pendekatan kualitatif fenomenologis yaitu menyelidiki suatu fenomena sosial atau masalah manusia. Qualitative methods departed from the phenomenological views, where researchers are trying to understand the meaning of events and linkages to ordinary people in certain situations (Kristiawan dan Tobari, 2017).

Nasution mengatakan dalam penelitian kualitatif tidak ada pilihan lainnya daripada menjadikan manusia sebagai instrumen penelitian yang utama karena segala sesuatu yang masih perlu dikembangkan sepanjang penelitian itu sendiri. Dalam keadaan yang serba tidak pasti dan jelas, tidak ada pilihan lain dan hanya peneliti sendiri sebagai alat satu-satunya yang dapat mencapainya (Sugiyono, 2009: 60).

Sumber data pada penelitian ini adalah 1) pengawas sekolah yang mendapat tugas sekolah binaan di SMP Negeri 44 Palembang; 2) kepala sekolah SMP Negeri 44 Palembang, dan beberapa guru SMP Negeri 44 Palembang. Selain itu, Sumber data yang lainnya ialah kata-kata dan tindakan, selebihnya adalah data tambahan seperti dokumen. Sumber data menurut Arikunto (2010:12) ada dua macam data yakni data primer dan data sekunder.

Teknik pengumpulan data yang utama dalam penelitian kualitatif bersifat nauralistik (alamiah), yakni dengan observasi, wawancara, dan dokumentasi. Wawancara digunakan untuk menjaring data atau informasi yang berkaitan dengan pelaksanaan supervisi akademik oleh pengawas sekolah (Wulandari dan Kristiawan, 2017). Metode observasi didefinisikan sebagai pengamatan 
akan manusia pada "habitatnya" (Yuliani dan Kristiawan, 2017). Instrumen penelitian yang utama merupakan peneliti sendiri dengan melakukan observasi, wawancara dan dokumentasi. Fokus pengamatan dilakukan pada tiga komponen utama, yaitu: actor (pelaku) space (ruang, tempat), dan activity (kegiatan). Selama penelitian berlangsung, peneliti memposisikan diri sebagai human instrument yang meluangkan banyak waktu di lapangan untuk di teliti. Analisis data yang digunakan dalam penelitian ini adalah analisis yang bersifat induktif.

\section{HASIL PENELITIAN DAN PEMBAHASAN}

Penelitian ini bertujuan untuk menginvestigasi pelaksanaan supervisi akademik oleh pengawas sekolah sebagai upaya peningkatan profesionalisme guru dalam meningkatkan mutu pendidikan pada SMP Negeri 44 Palembang. Dari sumber data (informan) tersebut diperoleh data meliputi: (1) uraian tentang teknik supervisi akademik; (2) uraian tentang kendala pelaksanaan supervisi akademik; (3) uraian tentang pelaksanaan supervisi akademik; (4) uraian tentang aspek-aspek yang disupervisi; dan (5) uraian tentang upaya yang dilakukan oleh pengawas sekolah dalam melaksanakan supervisi akademik. (6) frekuensi kunjungan pengawas sekolah dalam melaksanakan supervisi akademik.
Adapun data (hasil) yang diperoleh melalui penelitian ini adalah sebagai berikut: (1) pengawasan yang dilakukan dalam kegiatan supervisi menerapkan tiga model pendekatan, yakni: menggunakan pendekatan kedinasan, mitra kerja, dan kekeluargaan serta Teknik yang dikembangkan oleh pengawas dalam melaksanakan supervisi akademik di SMP Negeri 44 Palembang cukup bervariasi. Teknik-teknik supervisi itu adalah teknik supervisi individual (observasi kelas, kunjungan kelas, dan pertemuan individual), dan teknik supervisi kelompok (rapat supervise/pertemuan guru, kepanitiaan dan kerja kelompok seperti dalam MGMP); (2) Kendala pengawas dalam melaksanakan supervisi akademik di SMP Negeri 44 Palembang disebabkan jumlah guru sasaran supervisi yang banyak; kadangkala jadwal kunjungan kelas bentrok dengan kegiatan lain. Selain itu, masih ada guru yang enggan untuk disupervisi sehingga kegiatan supervisi kurang berjalan dengan baik, sehingga terbatasnya waktu, Jadwal kegiatan supervisi ada kalanya sering terganggu oleh kegiatan atau tugas lain, misalnya seperti rapat-rapat dinas, ikut workshop, dan kegiatan lainnya baik di tingkat kabupaten maupun di tingkat provinsi; (3) Pelaksanaan supervisi akademik oleh pengawas sekolah dapat mengubah kesadaran guru untuk meningkatkan kemampuan profesionalnya dan pengawas sekolah juga 
telah mampu melibatkan guru-guru senior sebagai pendamping dalam membantu kegiatan supervisi akademik. Pelaksanaan supervisi akademik di SMP Negeri 44 Palembang secara umum sudah cukup baik dan Mampu menjalankan tugas dan fungsinya sebagaimana mestinya, Pengawas sekolah cukup memahami supervisi akademik baik dilihat dari penerapan pola supervisi, penetapan waktu pelaksanaan supervisi, maupun fokus dari kegiatan supervisi tersebut; (4) aspek-aspek yang disupervisi oleh pengawas merupakan aspek perencanaan pembelajaran meliputi: program tahunan, program semester, silabus, Rencana Pelaksanaan Pembelajaran (RPP), agenda harian, daftar nilai, kriteria ketuntasan maksimal (KKM), kalender pendidikan, jadwal tatap muka, dan absensi siswa. aspek tindak lanjut kegiatan supervisi diarahkan pada upaya perbaikan mutu hasil pembelajaran, Aspek pelaksanaan KBM, pengelolaan kelas mulai dari kegiatan membuka, kegiatan inti, dan evaluasi pembelajaran aspek ini yang paling domonan di supervisi. Aspek-aspek yang menjadi sasaran supervisi akademik oleh pengawas sekolah di SMP Negeri 44 Palembang masih terbatas, belum semua aspek dalam supervisi akademik yang disupervisi oleh pengawas sekolah; (5) Frekuensi kunjungan pengawas sekolah dalam melaksanakan supervisi akademik di SMP Negeri 44 Palembang dianggap masih kurang. Hal tersebut dilihat dari belum meratanya jumlah atau banyaknya guru mendapatkan kegiatan supervisi akademik (kunjungan kelas) oleh pengawas sekolah; (6) Kegiatan supervisi akademik sudah dilakukan oleh pengawas sekolah bersama dengan kepala sekolah dan guru senior secara kontinu, dan berkesinambungan mulai proses supervisi, pra observasi, dan sampai kegiatan tindak lanjut demikian Upaya yang dilakukan oleh pengawas dalam melaksanakan supervisi akademik di SMP Negeri 44 Palembang belum optimal dalam pemberian pembinaan kepada para guru.

Sagala (2010 : 95) mengatakan kegiatan supervisi menaruh perhatian utama pada bantuan yang dapat meningkatkan kemampuan profesional guru. Kemampuan profesional ini tercermin pada kemampuan guru memberikan bantuan belajar kepada muridnya, sehingga terjadi perubahan perilaku akademik pada muridnya. Supervisi juga dilaksanakan oleh supervisor secara konstruktif dan kreatif dengan cara mendorong inisiatif guru untuk ikut aktif menciptakan suasana kondusif yang dapat membangkitkan suasana kreativitas peserta didik dalam belajar. Pendapat yang sama disampaikan oleh Ali Imron (2011:23) mengartikan bahwa supervisi pembelajaran adalah bantuan dalam wujud layanan profesional yang diberikan oleh orang 
yang lebih ahli dalam rangka peningkatan kemampuan profesional, teruama dalam proses belajar mengajar. Melalui kegiatan supervisi tersebut diharapkan terbaikinya proses belajar mengajar, yang di dalamnya melibatkan guru dan siswa, melalui serangkaian tindakan, bimbingan dan arahan. Terbaikinya proses belajar mengajar yang pencapaiannya antara lain melalui peningkatan kemampuan profesional guru tersebut diharapkan memberikan kontribusi bagi peningkatan mutu pendidikan. Peran pengawas dalam membina guru atau yang lebih dikenal dengan istilah supervisi pendidikan/pengajaran, kedudukannya sangat strategis dalam rangka meningkatkan kemampuan profesionalisme guru khususnya dalam kegiatan belajar mengajar. Oleh karena itu pengawas diharapkan mampu membimbing, membina, dan mendorong guru dalam memecahkan problematika kegiatan belajar mengajar yang dihadapi guru.

Peranan supervisor pendidikan yang disandang oleh pengawas dalam melaksanakan supervisi akademik harus dihindarkan tindakan-tindakan yang bersifat menyuruh atau menggurui, tetapi hendaknya harus dilakukan dengan pola pendekatan kemitraan dengan jalan mendukung, membantu, dan membagi tugas dan pekerjaan kepada seluruh komponen pendidikan. Imam Wahyudi (2012 : 48-49) mengemukakan delapan prinsip yang dapat digunakan dalam melakukan tindakan supervisi. Prinsip-prinsip itu mencakup sistematis, objektif, realistic, antisipatif, konstruktif, kreatif, kooperatif, dan kekeluargaan.

Sistematis, dalam arti supervisi dikembangkan dengan perencanaan yang matang sesuai dengan sasaran yang diinginkan. Objektif, artinya supervisi memberikan masukan sesuai dengan aspek yang terdapat dalam instrumen. Realistic, artinya supervisi didasarkan atas kenyataan sebenarnya, yaitu pada keadaan atau hal-hal yang sudah dipahami dan dilaksanakan oleh para staf sekolah. Antisipatif, artinya supervisi diarahkan untuk menghadapi kesulitankesulitan yang mungkin akan terjadi. Konstruktif, artinya supervisi memberikan saran-saran perbaikan kepada yang disupervisi untuk terus dikembangkan sesuai dengan ketentuan atau aturan yang berlaku. Kreatif, artinya supervisi mengembangkan kreatifitas dan inisiatif guru dalam mengembangkan proses pembelajaran. Kooperatif, artinya supervisi mengembangkan perasaan kebersamaan untuk menciptakan dan mengembangkan situasi pembelajaran yang baik. Kekeluargaan, artinya supervisi mempertimbangkan saling asah, asuh dan asih antarwarga sekolah yang sering dikenal dengan Tutwuri Handayani. 
Mengacu pada konsep, prinsip dan teknik supervisi serta peran profesional supervisor, pada tatanan tugas guru yang cukup kompleks diperlukan sebuah pendekatan supervisi yang betul-betul mampu mengarahkan dan memecahkan permasalahanpermasalahan yang dihadapi guru di kelas (dalam proses pembelajaran). Namun peran supervisor sering kali keluar dari koridor supervisi yang sebenarnya, seringkali supervisor bertindak sebagai seorang evaluator, supervisi dilakukan bukan karena kebutuhan yang dirasakan guru melainkan karena supervisor itu sendiri dituntut harus menjalankan tugasnya. Supervisi yang dilakukan secara tradisional cenderung tidak menyenangkan, maka interaksi antara guru dengan supervisor cenderung untuk dihindari dan dikurangi.

Upaya perbaikan mutu hasil pembelajaran yang menyangkut pelaksanaan KBM diarahkan pada pengelolaan kelas mulai dari kegiatan membuka, kegiatan inti, dan evaluasi pembelajaran tindak lanjut kegiatan supervisi diarahkan pada Kemampuan pada pengawas dalam menjalankan tugasnya sebagai supervisor pendidikan dalam penentuan materi supervisi, yakni terdiri dari perencanaan program meliputi: program supervisi yang berkaitan dengan administrasi guru sepeti program tahunan, program semester, silabus, Rencana Pelaksanaan
Pembelajaran (RPP), kalender pendidikan, jadwal tatap muka, agenda harian, daftar nilai, kriteria ketuntasan maksimal (KKM), dan absensi siswa.

Pengawas sekolah yang dilakukan dalam menjalankan fungsinya supervisor pendidikan tidak dapat dilepaskan dari beberapa kendala baik secara internal maupun eksternal. Secara internal kendala-kendala kegiatan supervisi dapat diidentifikasi Secara teknis kendala pengawas dalam mengadakan kegiatan supervisi seperti kendala yang berhubungan dengan kemampuan atau keterampilan sebagai supervisor, sedangkan kendala yang bersifat non-teknis diantaranya jika pengawas sakit sementara guru-guru yang lain kurang respon, maka jadwal kegiatan supervisi menjadi terkendala.

Berdasarkan fenomena bahwa pengawas sekolah selalu melibatkan kepala sekolah dan para guru dalam membentuk program pengawasan agar selalu melakukan sosialisasi program dan jadwal yang telah dibuatnya kepada guru dan kepala sekolah di sekolah tersebut. Hal ini tampak pada saat akan melakukan supervisi akademik yang selalu mendapat respon yang baik dari kepala sekolah dan para guru. Upaya yang dilaksanakan pengawas sekolah dalam melaksanakan supervisi akademik tersebut dapat berjalan dengan baik dan lancar sehingga berkat kemampuan yang dimiliki 
oleh pengawas sekolah agar selalu membina atau membangun komunikasi yang baik bersama para guru dan kepala sekolah.

Guru-guru yang akan diberikan supervisi menyambut dengan baik dan selalu siap ketika mengetahui ada pengawas sekolah yang datang ke sekolah untuk melakukan supervisi akademik sehingga Kepala sekolah selalu menunjukkan sikap yang bersahabat dan menganggap kehadiran pengawas di sekolah dirasakan membantu tugas dan akivitasnya guru di sekolah. karena berkat terjalinnya komunikasi dengan baik sehingga memberikan respon yang positif karena sudah memiliki persepsi yang sama mengenai program dan jadwal pelaksanaan supervisi akademik yang akan dilaksanakan di sekolah tersebut.

Kunjungan pengawas sekolah sangat lebih sering dan lebih banyak untuk membantu guru baik melalui kegiatan pemantauan, pembinaan, penilaian maupun pembimbingan dan pelatihan yang dilakasankan. Di sekolah ini sudah terbentuk budaya memuliakan tamu dan menghormati, siapa saja yang datang ke sekolah selalu disambut dan dilayani dengan baik mulai dari staf tata usaha, guru-guru sampai kepala sekolahnya sendiri tidak terkecuali pengawas sekolahnya sehingga para tamupun di sambut dengan baik.

Jika ketentuan jam kerja 37,5 jam dikaitkan dengan ekuivalen 24 jam tatap muka dapat diartikan bahwa seorang pengawas sekurang-kurangnya harus melaksanakan tugas pokok kepengawasan selama 24 jam tatap muka/pertemuan perminggu. Sisa waktu yang tersedia digunakan untuk kegiatan non tatap muka seperti: penyusunan program, laporan, pengembangan professional guru dan kegiatan pendukung lainnya yang ada disekolah.

\section{KESIMPULAN}

Dari temuan penelitian dan pembahasan hasil pada bagian terdahulu, maka pelaksanaan supervisi akademik oleh pengawas sekolah sebagai upaya peningkatan kemampuan profesionalisme guru dalam meningkatkan mutu pendidikan pada SMP Negeri 44 Palembang dapat disampaikan sebagai berikut (1) pengawasan yang dilakukan dalam kegiatan supervisi menerapkan tiga model pendekatan, yakni: menggunakan pendekatan kedinasan, mitra kerja, dan kekeluargaan serta Teknik yang dikembangkan oleh pengawas dalam melaksanakan supervisi akademik di SMP Negeri 44 Palembang cukup bervariasi. Teknik-teknik supervisi itu adalah teknik supervisi individual (observasi kelas, kunjungan kelas, dan pertemuan individual), dan teknik supervisi kelompok (rapat supervise/pertemuan guru, kepanitiaan dan kerja kelompok seperti dalam MGMP); (2) Kendala pengawas dalam melaksanakan 
supervisi akademik di SMP Negeri 44 Palembang disebabkan jumlah guru sasaran supervisi yang banyak; kadangkala jadwal kunjungan kelas bentrok dengan kegiatan lain. Selain itu, masih ada guru yang enggan untuk disupervisi sehingga kegiatan supervisi kurang berjalan dengan baik, sehingga terbatasnya waktu, Jadwal kegiatan supervisi ada kalanya sering terganggu oleh kegiatan atau tugas lain, misalnya seperti rapat-rapat dinas, ikut workshop, dan kegiatan lainnya baik di tingkat kabupaten maupun di tingkat provinsi; (3) Pelaksanaan supervisi akademik oleh pengawas sekolah dapat mengubah kesadaran guru untuk meningkatkan kemampuan profesionalnya dan pengawas sekolah juga telah mampu melibatkan guru-guru senior sebagai pendamping dalam membantu kegiatan supervisi akademik. Pelaksanaan supervisi akademik di SMP Negeri 44 Palembang secara umum sudah cukup baik dan Mampu menjalankan tugas dan fungsinya sebagaimana mestinya, Pengawas sekolah cukup memahami supervisi akademik baik dilihat dari penerapan pola supervisi, penetapan waktu pelaksanaan supervisi, maupun fokus dari kegiatan supervisi tersebut; (4) aspek-aspek yang disupervisi oleh pengawas merupakan aspek perencanaan pembelajaran meliputi: program tahunan, program semester, silabus, Rencana Pelaksanaan Pembelajaran (RPP), agenda harian, daftar nilai, kriteria ketuntasan maksimal (KKM), kalender pendidikan, jadwal tatap muka, dan absensi siswa. aspek tindak lanjut kegiatan supervisi diarahkan pada upaya perbaikan mutu hasil pembelajaran, Aspek pelaksanaan KBM, pengelolaan kelas mulai dari kegiatan membuka, kegiatan inti, dan evaluasi pembelajaran aspek ini yang paling domonan di supervisi. Aspek-aspek yang menjadi sasaran supervisi akademik oleh pengawas sekolah di SMP Negeri 44 Palembang masih terbatas, belum semua aspek dalam supervisi akademik yang disupervisi oleh pengawas sekolah; (5) Frekuensi kunjungan pengawas sekolah dalam melaksanakan supervisi akademik di SMP Negeri 44 Palembang dianggap masih kurang. Hal tersebut dilihat dari belum meratanya jumlah atau banyaknya guru mendapatkan kegiatan supervisi akademik (kunjungan kelas) oleh pengawas sekolah; (6) Kegiatan supervisi akademik sudah dilakukan oleh pengawas sekolah bersama dengan kepala sekolah dan guru senior secara kontinu, dan berkesinambungan mulai proses supervisi, pra observasi, dan sampai kegiatan tindak lanjut demikian Upaya yang dilakukan oleh pengawas dalam melaksanakan supervisi akademik di SMP Negeri 44 Palembang belum optimal dalam pemberian pembinaan kepada para guru. 


\section{DAFTAR PUSTAKA}

Ali Imron (2011). Supervisi Pembelajaran Tingkat Satuan Pendidikan. Jakarta: PT Bumi Aksara.

Dadan Wahidin (2009). Pentingnya Supervisi Pendidikan Sebagai Upaya Peningkatan Profesionalisme Guru. Jurnal terkemuka Manajemen Pendidikan, Educational Leadership.

Daryanto (2009). Panduan Proses Pembelajaran Kreatif dan Inovatif. Jakarta, AV Publisher.

Depdiknas Republik Indonesia (2003). Undang-Undang Republik Indonesia Nomor 20 Tahun 2003 Tentang Sistem Pendidikan Nasional. Jakarta, BP. Panca Usaha.

Jerry H. Makawimbang (2011). Supervisi dan Peningkatan Mutu Pendidikan. Bandung, Alfabeta.

Kristiawan, M., \& Elnanda, D. (2017). The Implementation of Authentic Assessment in Cultural History of Islam Subject. AlTa lim Journal, 24(3).

Kristiawan, M., Safitri, D., \& Lestari, R. (2017). Manajemen Pendidikan. Yogyakarta: Deepublish

Kristiawan, M. (2017). The Characteristics of the Full Day School Based Elementary School. Transylvanian Review, 1(1).

Mathew B. Miles and A. Michael Huberman (2009). Analisis Data Kualitatif.Jakarta, Universitas Indonesia.

Ngalim Purwanto (2009). Adminisrasi dan Supervisi Pendidikan. Bandung, PT Remaja Rosdakarya.

Nurhayati (2006). Berbagai Pendekatan Dalam Pembelajaran (Faktor-Faktor Yang Mempengaruhi Profesionalisme dan Kinerja Guru Biologi di SMAN Kota
Makasar Sulawesi Selatan). Bandung, Jurnal Pendidikan No. 4 tahun XXV 2006.

Sugiyono (2009). Memahami Penelitian Kualitatif. Bandung, Alfabeta.

Syaiful Sagala (2010). Supervisi Pembelajaran. Dalam Profesi Pendidikan.Bandung, Alfabeta.

Uus Ruswenda (2011). Berbagai Faktor Dalam Supervisi Akademik Pengawas Sekolah Menengah Kejuruan (SMK) Di Kabupaten Kuningan. Tesis. Jakarta: Fakultas Ilmu Sosial dan Ilmu Politik Program Studi Ilmu Administrasi Kekhususan Administrasi dan Kebijakan Pendidikan. Universitas Indonesia.

Wulandari, Y., \& Kristiawan, M. (2017). Strategi Sekolah dalam Penguatan Pendidikan Karakter Bagi Siswa dengan Memaksimalkan Peran Orang Tua. JMKSP (Jurnal Manajemen, Kepemimpinan, dan Supervisi Pendidikan), 2(2).

Yuliani, T., \& Kristiawan, M. (2017). Peran Kepemimpinan Kepala Sekolah dalam Membina Kompetensi Sosial (Pelayanan Prima) Tenaga Administrasi Sekolah. JMKSP (Jurnal Manajemen, Kepemimpinan, dan Supervisi Pendidikan), 1(2). 